\title{
A informalização da Justiça Penal no Brasil
}

\author{
Rodrigo Ghiringhelli de Azevedo
}

\section{O movimento de informalização da Justiça}

Tendo de responder à crise fiscal do Estado, ao aumento da demanda por controle penal, ao debilitamento dos mecanismos de controle comunitário e à perda de legitimidade do próprio sistema de controle penal formal, as novas estratégias de controle vão buscar saídas incorporando a contribuição dos estudos sócio-antropológicos que tiveram por objeto o sistema jurídico. Na esfera penal, estas reformas são operadas através dos mecanismos de informalização processual para as chamadas "pequenas desordens sociais" (petits désordres sociaux), conforme o modelo francês, ${ }^{2}$ "pequenas reclamações" (small claim), nos EUA, ou "situações problemáticas”, no jargão abolicionista, através de mudanças na legislação, uma vez que a lei criminal constitui a instância e o operador primário da seleção e do controle da delinqüência. ${ }^{3}$

${ }^{1}$ Advogado, mestre e doutorando em Sociologia pela Ufrgs, professor na Pucrs. Contatos com o autor: rgdeazevedo@uol.com.br. (1994).

${ }^{2}$ Para uma exposição a respeito da regulação desse tipo de conflito na França, vide Costa-Lascoux

${ }^{3}$ Sobre os movimentos de descriminalização e neocriminalização, vide Figueiredo Dias e Costa Andrade (1992: 397-441) e Cervini (1995); sobre o papel da norma penal na seleção e controle da delinqüência, vide Bergalli (1991). 
Embora as formas do sistema penal estejam sempre em mutação, acompanhando a morfologia da sociedade na qual exercem o seu poder de regulação dos comportamentos e os interesses e representações dos responsáveis pela sua concepção e execução, o atual movimento de informalização dos procedimentos judiciais assume uma característica singular: surge tanto como função intra-sistêmica, derivada das razões próprias da lógica de redução da complexidade e da demanda por controle social formal nas sociedades contemporâneas, como de uma transformação do "ambiente simbólico" ou da "consciência coletiva" que limita a intervenção do Estado sobre a sociedade.

Quer se fundamentem na necessidade de redução da complexidade e da turbulência do meio social, estabilizando as relações entre os integrantes da sociedade civil e desta com o Estado, quer privilegiem uma perspectiva instrumental de acessibilidade, eficácia e economia administrativa, as chamadas soluções conciliatórias ou informalizantes visam promover a interação face-a-face entre vítima e acusado como forma de superar o conflito que está na origem do suposto fato delituoso.

Nas heterogêneas comunidades urbanas contemporâneas, os programas de mediação e informalização da justiça penal obtêm rápida adesão graças à insatisfação com as sanções penais tradicionais para a solução de disputas e conflitos interpessoais, e apelam para as estruturas existentes da comunidade, embora muitas vezes não passem de um apêndice do sistema legal formal. De qualquer forma, correspondem à busca de alternativas de controle mais eficazes e menos onerosas do que as oferecidas pelo sistema penal tradicional, que permitam um tratamento individualizado, particularista, de cada caso concreto, ao invés da orientação pela generalidade e universalidade das normas jurídicas.

Em uma análise circunscrita aos modelos de informalização adotados em diversos estados norte-americanos, identificou-se uma importante diferenciação, embora determinadas características fossem recorrentes. ${ }^{4}$ Em alguns casos, a ênfase é colocada na mediação como processo terapêutico e a pressão da comunidade é o meio para alcançar soluções voluntariamente acordadas entre as partes, no interior das cortes tradicionais. Em outros casos, se colocam como uma alternativa ao sistema formal, como as chamadas "community courts", que têm jurisdição exclusiva sobre certas ofensas. A corte comunitária tem funções conciliatórias e

\footnotetext{
${ }^{4}$ Para ter uma amostra das pesquisas empíricas sobre a informalização da justiça norte-americana, vide Selva e Bohm (1987); Hughes e Schneider (1989); Palumbo e Musheno (1994); vide também a tese de Oliveira (1989), em que analisa as sessões de mediação de pequenas causas cíveis de um ponto de vista antropológico.
} 
adjudicatórias, e os mediadores são eleitos pela comunidade onde residem e recebem um treinamento formal mínimo. Esse modelo se aproxima da chamada democracia participativa, com o envolvimento maior da comunidade em questões antes restritas e resolvidas pelo aparato estatal.

Em que pese a existência de modelos diferenciados, os elementos conceituais que configuram um tipo ideal de informalização da justiça nos estados contemporâneos são os seguintes: uma estrutura menos burocrática e relativamente mais próxima do meio social em que atuam; aposta na capacidade dos disputantes promover sua própria defesa, com uma diminuição da ênfase no uso de profissionais e da linguagem legal formal; preferência por normas substantivas e procedimentais mais flexíveis, particularistas, ad hoc; mediação e conciliação entre as partes mais do que adjudicação de culpa; participação de não juristas como mediadores; preocupação com uma grande variedade de assuntos e evidências, rompendo com a máxima de que "o que não está no processo não está no mundo"; facilitação do acesso aos serviços judiciais para pessoas com recursos limitados para assegurar auxílio legal profissional; um ambiente mais humano e cuidadoso, com uma justiça resolutiva rápida, e ênfase em uma maior imparcialidade, durabilidade e mútua concordância no resultado; geração de um senso de comunidade e estabelecimento de um controle local através da resolução judicial de conflitos; maior relevância em sanções não coercitivas para obter acatamento.

\section{A informalização da justiça penal no Brasil}

No Brasil, a incorporação dessas inovações no sistema judicial teve impulso a partir do final dos anos 80 , em especial após a promulgação da Constituição de 1988. Uma série de novos mecanismos para a solução de litígios foram previstos, com vistas à agilização dos trâmites processuais, entre os quais têm um significado relevante os Juizados Especiais Cíveis e Criminais, voltados para as chamadas pequenas causas e para os delitos de menor potencial ofensivo, regulamentados pela Lei Federal nº 9.099, de setembro de 1995.

A implantação dos Juizados Especiais Criminais (JEC) integra uma lógica de informalização, entendida não como a renúncia do Estado ao controle de condutas e no alargamento das margens de tolerância, mas como a procura de alternativas de controle mais eficazes e menos onerosas (Dias e Andrade 1992, p. 403). Para os Juizados Especiais Criminais vão confluir determinados tipos de delitos (com pena máxima em abstrato até um ano) e de acusados (não reincidentes). Com a sua implantação, se esperava que as antigas varas criminais pudessem atuar com maior prioridade sobre os chamados crimes de maior potencial ofensivo. 
Promulgada a Lei 9.099/95 em setembro de 1995, o rito processual nela previsto passou a ser imediatamente aplicado, pelas Varas Criminais comuns, para os delitos de menor potencial ofensivo, especialmente a suspensão condicional do processo e as novas alternativas de conciliação entre vítima e autor do fato e de transação entre Ministério Público e autor do fato. Porto Alegre foi uma das primeiras comarcas de grande porte do país a criar os Juizados Especiais Criminais, que passaram a ter competência exclusiva para o processamento dos delitos previstos na lei 9.099/95, com a edição da Lei Estadual $n^{\circ} 10.675$, em 2 de janeiro de 1996, que criou o Sistema dos Juizados Especiais Cíveis e Criminais no Estado do Rio Grande do Sul.

A Lei 9.099/95 deu aos Juizados Especiais Criminais a competência para a conciliação e o julgamento das infrações penais de menor potencial ofensivo, que compreendem as contravenções penais (Decreto-Lei ${ }^{\circ} 3.688$, de 03.10.1941) e os crimes a que a lei penal comine pena máxima não superior a um ano de detenção ou reclusão, excetuados os delitos para os quais está previsto procedimento especial.

Até a edição da Lei 9.099/95, as contravenções penais e os delitos punidos com pena de detenção eram processados pelo rito processual previsto no Capítulo V, Título II, do Livro II (art. 531 a 540) do Código de Processo Penal, denominado Processo Sumário. Pouca diferença havia entre este tipo de procedimento e o Processo Ordinário, aplicado aos delitos apenados com reclusão. A lei previa apenas a redução de alguns prazos e o abreviamento de determinados momentos processuais, mas a estrutura do processo era basicamente a mesma: inquérito policial, denúncia do Ministério Público, interrogatório do réu, defesa prévia, audiência de instrução, debates orais, julgamento. Não havia a possibilidade de reparação civil dos danos sofridos pela vítima no próprio processo penal, ficando relegada ao papel de mera informante da justiça penal. Nem tinha o réu qualquer interesse em reconhecer o fato que lhe era imputado, com a negociação em torno da pena.

De acordo com o que estabeleceu o legislador no art. 62 da Lei 9.099/95, o processo perante os Juizados Especiais Criminais deve ser orientado pelos critérios da oralidade, informalidade, economia processual e celeridade, objetivando, sempre que possível, a reparação dos danos sofridos pela vítima e a aplicação de pena não privativa de liberdade. Dispensando a realização do inquérito policial, a Lei 9.099/95 determina que a autoridade policial, ao tomar conhecimento do fato delituoso, deve imediatamente lavrar um termo circunstanciado do ocorrido e encaminhá-lo ao Juizado, se possível com o autor do fato e a vítima, providencian- 
do a requisição dos exames periciais necessários para a comprovação da materialidade do fato (art. 69). Não sendo possível o comparecimento imediato de qualquer dos envolvidos ao juizado, a secretaria do juizado deverá providenciar a intimação da vítima e do autor do fato, por correspondência com aviso de recebimento, para que compareçam à audiência preliminar (art. 71).

$\mathrm{Na}$ audiência preliminar, presente o representante do Ministério Público, o autor do fato e a vítima, acompanhados de advogado, o juiz esclarecerá sobre a possibilidade de composição dos danos, assim como sobre as conseqüências da aceitação da proposta de aplicação imediata de pena não privativa de liberdade ao autor do fato (art. 72). Nos crimes de ação penal privada e de ação penal pública condicionada à representação, o acordo para composição dos danos extingue a punibilidade. Não obtido o acordo, o juiz dá imediatamente à vítima a oportunidade de exercer o direito de oferecer queixa-crime ou representação verbal (art. 75).

Havendo queixa-crime ou representação ou sendo o crime de ação penal pública incondicionada, o Ministério Público poderá propor ao autor do fato a transação penal, com a aplicação imediata de pena restritiva de direitos ou multa, a não ser no caso do acusado ser reincidente, ou no caso de "não indicarem os antecedentes, a conduta social e a personalidade do agente, bem como os motivos e as circunstâncias, ser necessária e suficiente a adoção da medida" (art. 76). Não aceita a proposta, o representante do Ministério Público oferecerá ao juiz, de imediato, denúncia oral, e o processo seguirá o rito sumaríssimo, previsto na Lei 9.099/ 95.

Oferecida a denúncia, poderá ainda o representante do Ministério Público propor a suspensão do processo por dois a quatro anos, desde que o agora denunciado não esteja sendo processado ou não tenha sido condenado por outro crime. A suspensão será revogada se, no curso do prazo, o denunciado for processado por outro crime ou descumprir qualquer outra condição imposta. Expirado o prazo sem revogação, o juiz declarará extinta a punibilidade.

Caso não seja possível a suspensão do processo, o juiz deverá intimar as partes para a audiência de instrução e julgamento, que se inicia com a resposta oral da defesa à acusação formulada na denúncia ou queixa-crime. Aceita a argumentação da defesa, o juiz não recebe a denúncia ou queixa e encerra o processo. Recebida a denúncia ou queixa, são ouvidas a vítima e as testemunhas de acusação e de defesa, o acusado é interrogado e realizam-se os debates orais entre defesa e acusação. Em seguida o juiz profere a sentença final condenatória ou absolutória. 
Os recursos previstos pela Lei 9.099/95 são a apelação (em caso de sentença condenatória ou absolutória ou da decisão de rejeição da denúncia ou queixa) e os embargos de declaração (em caso de obscuridade, contradição, omissão ou dúvida na sentença), e são encaminhados a uma Turma Recursal composta de três juízes em exercício no primeiro grau de jurisdição.

\section{Os Juizados Especiais Criminais seis anos depois de sua implantação}

Seis anos depois da entrada em vigor da Lei 9.099/95, que implantou os Juizados Especiais Cíveis e Criminais no Brasil, é possível e necessário realizar um balanço dos efeitos produzidos por esta inovação procedimental, especialmente no tocante à informalização da justiça penal, com a introdução dos mecanismos da conciliação e da transação penal para a solução de delitos de menor potencial ofensivo.

Um dos fatos geradores de ambiguidade nas avaliações a respeito dos Juizados Especiais Criminais relaciona-se com as diferentes motivações que estiveram na origem do processo de elaboração da Lei 9.099/95, e que se expressam também no discurso dos comentadores da legislação, que acabam por imprimir a sua marca nas práticas judiciárias. São três as perspectivas através das quais é possível defender a necessidade de reformas procedimentais no sentido da informalização da justiça: a) a busca pela efetivação de direitos, através da ampliação do acesso à justiça; b) a busca da conciliação como objetivo primordial do processo judicial, especialmente nos chamados delitos de menor potencial ofensivo, dando à vítima a possibilidade de participação efetiva e reparação do dano sofrido; c) a busca da diversificação das instâncias judiciais como resposta à morosidade e ao congestionamento da Justiça (Garth 1982: 183-212).

Para o movimento pela efetivação de direitos, as reformas informalizantes são vistas em geral como uma alternativa para dar eficácia aos direitos de setores sociais vulneráveis. Se manifesta pelo esforço em garantir acesso a advogados, agências administrativas e a toda estrutura de disputa processual. O principal método utilizado é a promoção de acessibilidade através de mudanças no pessoal e nos procedimentos legais, algumas das quais no sentido da informalização. Esforços para prover representação legal para implementação dos direitos de grandes grupos de consumidores, vítimas da poluição e outros danos ambientais, e vítimas de relações continuadas de violência doméstica, contribuíram para a inovação em matéria procedimental. 
Uma avaliação do impacto que essa perspectiva produziu em diversos países permite concluir que um sério comprometimento em tornar efetivos os direitos das camadas sub-privilegiadas, ampliando o seu acesso ao judiciário, exige gastos. É necessário criar novas instituições judiciais, renovar as antigas, tornando-as mais acessíveis, e investir no treinamento e remuneração não apenas de juízes e promotores, mas também de defensores públicos para as partes.

Desse ponto de vista, o estudo do funcionamento dos Juizados Especiais Criminais demonstra que a abolição do inquérito policial para os delitos de menor potencial ofensivo garantiu às vítimas o acesso ao judiciário, que antes lhes era negado. Por outro lado, a estrutura cartorária e hermética do sistema judicial ainda permanece intocada. A dinâmica de funcionamento da Justiça, com uma demanda enorme de processos, e a pressão exercida por parte das corregedorias de justiça para que os juízes tenham alta produtividade, aferida pelo número de processos concluídos, acaba levando à adoção de rotinas muitas vezes à margem das previsões legais, como a realização de audiências sem a presença do Ministério Público, sem defensores constituídos para autor do fato e vítima, e especialmente o privilegiamento da transação penal sobre a conciliação, já que esta última exigiria uma maior preocupação dos magistrados/conciliadores em restabelecer o diálogo entre as partes.

A consequência perversa e não prevista desta dinâmica é a enorme insatisfação da vítima, cujo objetivo da Lei era incorporar ao processo penal, e que acaba, ao constatar a falta de preocupação com a resolução do conflito que está por trás do delito de menor potencial ofensivo, sentindo-se impotente e descrente da utilidade do sistema judicial. Resgatar a idéia original de uma participação maior da vítima não significa desconsiderar os direitos do acusado ou submetê-lo a uma nova forma de vingança privada, e sim o investimento do sistema na conciliação como forma de recomposição de laços sociais que foram rompidos. Para que isto aconteça, seria preciso lançar mão de medidas como a participação dos agressores em programas interdisciplinares de controle da violência, através da reflexão e do apoio psicológico, única forma de romper com práticas arraigadas de resolução de conflitos pelo recurso à violência física ou psíquica, especialmente no ambiente doméstico e de vizinhança.

Quanto aos operadores do direito envolvidos com o fluxo dos delitos de menor potencial ofensivo, ainda há grande incompreensão quanto ao novo papel que lhes compete nos Juizados Especiais. A autoridade policial, dispensada da realização do inquérito, tem agora a tarefa de produção do termo circunstanciado. No mo- 
mento da lavratura do termo, seria indispensável uma informação clara à vítima e ao autor do fato sobre a nova sistemática processual, assim como a marcação imediata da audiência, já que o imediato acionamento da máquina judiciária seria um ganho importante frente ao processo penal tradicional, de forma a garantir uma atuação efetiva do sistema judicial para a mediação da conflitualidade social. Têm sido bem sucedidas as iniciativas visando dar às polícias militares a possibilidade de elaboração dos termos circunstanciados, já que o monopólio de sua elaboração nas mãos da Polícia Civil dificulta o rápido encaminhamento e duplica a burocracia policial de forma desnecessária.

Falta ou omissão dos promotores no momento das audiências, ausência de defensores públicos para o atendimento da vítima e do autor do fato, salas de audiência estruturadas de forma tradicional, com o juiz em plano acima das partes, e utilizando-se da autoridade que detém sobre elas para acelerar o encerramento dos processos, critérios de produtividade baseados exclusivamente no número de casos encerrados, todos estes são indicadores de que o problema do acesso à justiça estatal não está resolvido, e depende mais da iniciativa administrativa dos setores que gerenciam o sistema do que de uma nova disposição legal.

Por fim, uma postura mais ativa das vítimas para buscar a judicialização do conflito que produziu a vitimização depende também de iniciativas da sociedade civil para ampliar o acesso às informações quanto ao funcionamento do sistema legal, assim como da preparação e custeio de profissionais aptos para garantir uma representação eficaz nas instâncias judiciais. Entidades vinculadas à proteção das vítimas de violência doméstica são as que têm obtido melhores resultados no encaminhamento dessas questões, ampliando a noção de esfera pública para além do espaço estatal.

O enfoque da conciliação preocupa-se não com a defesa de direitos, mas em resolver disputas em termos aceitáveis para as partes. Embora não haja uma contradição necessária entre a conciliação e a efetivação de direitos, a ideologia de seus proponentes e sua atual aplicação sugerem que o mecanismo da conciliação tende, em alguns casos, a solapar a efetivação de direitos. Alguns dos seus defensores reconhecem que a sua utilização somente é viável para certos casos bastante específicos, para conciliação entre indivíduos. Diante da crise de instituições como a família e a escola, a conciliação governamental nessas situações de conflitualidade interindividual poderia ter uma função bastante útil. Seus defensores sustentam que, em pequenos delitos ou quase delitos, disputas entre vizinhos, ou certos conflitos intra-familiares, conciliadores comunitários, empregando padrões de senso 
comum, poderiam contribuir para manter a coesão social na comunidade. O conciliador ou mediador tenderia a apelar para os interesses comuns de ambas as partes, para evitar a lentidão e os custos financeiros e psicológicos de um processo judicial, propondo às partes uma espécie de jogo de soma positiva, ao invés da soma zero de uma decisão que declara um vencedor e um perdedor.

Tratando-se na sua grande maioria de conflitos no ambiente doméstico ou de vizinhança, em que uma das partes apela para o exercício da violência física (lesões) ou psicológica (ameaça) a fim de manter uma relação de dominação crescentemente questionada, como é o caso da dominação patriarcal, em que o rompimento do diálogo leva a uma espiral degenerada de comunicação, não há dúvida que a resposta tradicional do sistema penal, com a apropriação do conflito pelo Estado e o recurso à punição, não resolve o problema e gera a estigmatização e os altos índices de reincidência dos egressos do sistema prisional, e consequentemente a sobrevitimização da família do autor do fato.

Quando a opção dos juízes é no sentido do restabelecimento do diálogo entre as partes, mais do que a pura e simples aplicação das fórmulas legais, há uma elevada possibilidade de que obtenha o reconhecimento da culpa, a reparação dos danos e o restabelecimento de uma base mínima de sociabilidade que impeça o recurso à violência. Isso, no entanto, é dificultado por um habitus profissional dos magistrados no qual não há espaço para diálogo com as partes em audiência, e onde a resolução dos conflitos fica em segundo plano em relação à decisão quanto à autoria e materialidade do fato. Talvez fosse necessário utilizar uma prerrogativa prevista na Lei 9.099/95, para a incorporação de mediadores leigos, tal como ocorre nos Juizados Especiais Cíveis, que conduziriam a audiência de conciliação, visando efetivamente o restabelecimento do diálogo entre as partes em conflito, e buscando solucionar a demanda com a reparação do dano e o compromisso de respeito mútuo.

Por outro lado, quando não há a possibilidade de conciliação, a transação penal precisa ser proposta não como uma maneira de encerrar o processo sem maiores consequências, pelo puro e simples pagamento de uma multa ou a entrega de cestas básicas a pessoas carentes. A prestação pecuniária não traz nenhuma vantagem nos delitos que envolvem conflitualidade interpessoal, sendo muito mais eficaz a proposta de uma pena de prestação de serviços à comunidade, que incorpore o acompanhamento do autor do fato durante um determinado período, visando a superação efetiva da situação de conflito em que estava envolvido e do padrão de comportamento adotado. 
A terceira perspectiva é a da diversificação, cuja ênfase é colocada no problema do congestionamento da justiça formal. Propugna pelo processamento de disputas fora dos tribunais, por meio de acordo, conciliação ou arbitragem. Seus defensores sustentam que o congestionamento da justiça não será resolvido com a mera ampliação do número de juízes e tribunais.

No caso brasileiro, a criação dos Juizados Especiais Criminais, com a possibilidade de atuação de conciliadores leigos, foi determinada pela própria Constituição, afastando em princípio qualquer óbice quanto à sua viabilidade constitucional. Aqui, no entanto, ao invés de desafogar as Varas Criminais, a adoção de medidas informalizantes, em especial a abolição do inquérito policial, abriu as portas das salas de audiência para delitos que ficavam engavetados nos escaninhos das delegacias. Mas para dar conta desta nova demanda é forçoso reconhecer que os procedimentos tradicionais seriam absolutamente incompatíveis com a necessidade de encaminhar milhares de processos de forma rápida e socialmente útil, o que somente vem se tornando possível com a implantação dos Juizados Especiais.

No entanto, a excessiva preocupação com a celeridade da justiça, aliada a problemas estruturais como a falta de juízes, promotores e defensores públicos e o número insuficiente de Juizados, junto com a demanda impressionante de processos judiciais, acaba por solapar a possibilidade de que as audiências sirvam como um momento para o restabelecimento do diálogo entre as partes em conflito. A busca de produtividade leva a uma tendência de redução dos esforços do juiz no sentido da conciliação, que exigiria o esclarecimento das partes e a abertura de espaço para a expressão da vítima e do autor do fato.

Seja qual for a perspectiva adotada, a conclusão a que se chega é de que ainda estamos muito distantes de uma situação de maior acesso à justiça às vítimas de violência, de investimento na conciliação como forma mais adequada para o enfrentamento da conflitualidade social, e de instâncias judiciais efetivamente capazes de dar conta, de maneira satisfatória, da prestação de serviços judiciais essenciais ao exercício da cidadania e à pacificação social. Todos os problemas elencados, no entanto, não podem servir para desestimular a busca por um novo paradigma de justiça penal, que passa necessariamente pelo aperfeiçoamento dos caminhos abertos pela Lei 9.099/95. Um olhar sociológico sobre os resultados práticos dessa mudança pode sem dúvida contribuir para mostrar que, para além das limitações legais, as maiores dificuldades para a concretização deste novo paradigma se situam nas próprias estruturas do sistema penal, em todas as suas instâncias, e nas práticas dos operadores do direito. Neste âmbito, muito ainda há 
que ser feito, mas os resultados alcançados por algumas experiências inovadoras na formação de operadores, e no tratamento interdisciplinar da conflitualidade social, dão mostras de que ainda é possível resgatar a idéia dos Juizados como um novo modelo de justiça penal.

\section{Referências bibliográficas}

Bergalli, Roberto (1991). Sociology of penal control within the framework of the Sociology of Law. Oñati Proceedings n ${ }^{\circ}$ 10, I.I.S.L., p. 25-45.

Cervini, Raúl (1995). Os processos de descriminalização. São Paulo: Ed. Revista dos Tribunais.

Costa-Lascoux, Jacqueline (1994). La Régulation des petits désordres sociaux. Les Cahiers de La Sécurité Intérieure n 18 , p. 139-158.

Dias, Jorge de Figueiredo e Manuel da Costa Andrade (1992). Criminologia: o homem delinqüente e a sociedade criminógena. Coimbra: Ed. Coimbra, $1^{\text {a }}$ reimpressão.

Garth, Bryant (1982). The movement toward procedural informalism in North America and Western Europe: a critical survey. In: Abel (org.), The politics of informal justice v. 2, New York: Academic Press.

Hughes, Stella e Anne Schneider (1989). Victm-offender mediation: a survey of program characteristics and perceptions of effectiveness. Crime e Delinquency v. $35, n^{\circ} 2$.

Oliveira, Luis Roberto Cardoso de (1989). Fairness and communication in small claims courts. Harvard University, mimeo.

Palumbo, Denis e Michael Musheno (1994). The political construction of alternative dispute resolution and alternatives to incarceration. Arizona State University, mimeo.

Selva, Lance e Robert Bohm (1987). A Critical examination of the informalism experiment in the administration of justice. Crime and Social Justice $\mathrm{n}^{\circ} 29, \mathrm{p}$. 43-57. 
